\title{
Alignment between ICT and communication in construction projects
}

\section{Arjen M. Adriaanse*, Hans Voordijk and Geert P.M.R. Dewulf}

Department of Construction Process Management, Technology and Management, University of Twente, P.O. Box 217, 7500 AE Enschede, The Netherlands Fax: +31 $534892511 \quad$ E-mail: a.m.adriaanse@sms.utwente.nl E-mail: h.voordijk@sms.utwente.nl E-mail: g.p.m.r.dewulf@sms.utwente.nl ${ }^{*}$ Corresponding author

\begin{abstract}
Through rapid advancements in ICT, opportunities arise in enhancing communication between participants of different organisations in construction projects. The use of ICT in construction is, however, relatively limited and ineffective compared to other sectors such as the automotive or the aerospace industry. An understanding of the project context and the nature of communication between organisations is an essential prerequisite in analysing and designing ICT in an effective way. The objective of this paper is to analyse the alignment between ICT and the actual communication processes in construction projects. The major question is what types of action need to be supported by ICT, and those that can be supported by the available ICT applications in construction projects. The critical social theory of Habermas $(1984,1987)$ is used as a classification scheme for analysing the alignment of communication and ICT applications in construction projects.
\end{abstract}

Keywords: action types; ICT; construction projects.

Reference to this paper should be made as follows: Adriaanse, A.M., Voordijk, H. and Dewulf, G.P.M.R. (2004) 'Alignment between ICT and communication in construction projects', Int. J. Human Resources Development and Management, Vol. 4, No. 4, pp.346-357.

Biographical notes: Arjen Adriaanse is Researcher at the Department of Construction Process Management at the University of Twente, The Netherlands. His research focuses on the development and the use of inter-organisational ICT, especially in construction projects. He is interested in the social and behavioural aspects in the development and use of this ICT. $\mathrm{He}$ also is a Consultant at Balance \& Result Management Consultants focussing on the same subjects. Arjen Adriaanse received his masters' degree in civil engineering and management from the University of Twente.

Hans Voordijk is Associate Professor at the Department of Construction Process Management at the University of Twente, The Netherlands. His research, consultancy and lecturing is in the two following fields: supply chain management and ICT in the construction industry, and location dynamics of production and distribution facilities of global manufacturers. Hans holds a $\mathrm{PhD}$ in Economics from Maastricht University. He has papers published in journals such as International Journal of Operations and Production Management, Supply Chain Management: An International Journal, 
International Journal of Logistics, Construction Management and Economics, and the European Journal of Purchasing and Supply Management.

Geert Dewulf is Professor of Planning and Development and Head of the Department of Construction Process Management at the University of Twente, The Netherlands. Before he joined Twente University, he was a Senior Consultant on urban planning at the Netherlands Organisation of Applied Scientific Research and an Assistant Professor at Delft University of Technology, and the University of Utrecht, and a Fellow at Harvard University. He holds a PhD in Social Sciences of the University of Utrecht. Geert Dewulf has an extensive list of publications on real estate management, planning and development, and future studies.

\section{Introduction}

In construction projects, a large number of different activities have to be executed by many participants of different organisations working simultaneously together. The result is a huge amount of information that has to be communicated (Dawood et al., 2002; Kornelius and Wamelink, 1998; Pietroforte, 1997). Communication in construction is therefore a matter of vital importance (e.g., Dawood et al., 2002; Mohamed and Stewart, 2003; Thorpe and Mead, 2001). Although sharing information is critical for the success of construction projects, the construction industry is confronted with great difficulties in sharing information among its participants. Therefore, there has been an increasing recognition of the need for a more effective and efficient transfer of information between participating organisations in construction projects (e.g., Ahmad et al., 1995; Baldwin et al., 1999; Tserng and Lin, 2003).

Through rapid advancements in information and communication technologies (ICT), opportunities arise in enhancing communication between participants in construction projects and in enabling effective and efficient communication (Anumba and Ruikar, 2002; Dawood et al., 2002; Egbu et al., 2001; Ahmad et al., 1995). The construction industry has now started recognising the potential advantages of these systems (Egbu et al., 2001; Anumba and Ruikar, 2002), but both literature and practice point out that available and often easily accessible technology is not being utilised completely (Egbu et al., 2001). The use of these systems in construction is relatively limited and ineffective compared to other sectors such as the automotive or aerospace industry (Anumba and Ruikar, 2002). The effectiveness of utilising ICT in construction projects could be hindered by the inability to share electronic data between organisations (Hassan and McCaffer, 2002; Mohamed and Stewart, 2003).

The development of new ICT applications often leads towards the use of these technologies without a proper investigation of the advantages and disadvantages of the new technologies (Wamelink and Wortmann, 1996). As a result, participants within construction projects use only a small fraction of the possibilities of the ICT they introduced or software is not aligned for the specific purpose. This can be explained by the structuration theory. The structuration theory suggests that human actions are enabled and constrained by structures (Giddens, 1979, 1984). These structures are the result of previous actions. Rules and resources (i.e., structure) mediate human action and are at the same time reaffirmed through being used by human actors. Several scholars have used 
this structuration theory in order to investigate the design, development, and use of technology (e.g., DeSanctis and Poole, 1994; Orlikowski, 1992; Orlikowski and Yates, 1994). Technology is created and changed by human action, but is also used by humans to accomplish some action (Orlikowski, 1992). When a technology is developed by an organisation and used by another organisation, the developing organisation plays an influential role in shaping the social practices of the organisation using the technology. When ICT is not used as it was intended, the objectives of the technology's designers might be undermined. Literature points out that ICT vendors face difficulties in identifying the construction industry's ICT needs and requirements (Hassan and McCaffer, 2002). Before ICT is designed and introduced in order to support communication, attention has to be devoted to the actual communication processes in construction projects (i.e., the pre-existing structures). An understanding of the nature of communication between organisations is an essential prerequisite in analysing and designing ICT in an effective way.

In order to enable effective and efficient communication between organisations in construction projects, ICT needs to be aligned with the actual communication processes. During the design and development of ICT, the actual communication processes need to be taken into account. In this paper, the focus is on the alignment between ICT and the actual communication processes in construction projects. The objective of this paper is to analyse what types of action need to be supported by ICT, and those that can be supported by ICT applications. This alignment needs attention because otherwise advances in ICT will not be utilised in construction in the future. For managerial practice, this leads to a more articulated view on the alignment between ICT applications and the communication in construction projects, and shows directions for ICT developments in the future.

The paper has the following structure. In Section 2, a classification scheme based on the Critical Social Theory of Habermas is presented. In Section 3, ICT applications developed for the construction industry are analysed. The classification scheme is used to analyse the characteristics of the developed ICT applications. In Section 4, communication between organisations in construction projects is discussed and also related to Habermas' classification scheme. In Section 5, the alignment between the communication in construction projects and ICT applications developed to enhance communication in construction is analysed.

\section{Habermas' critical social theory}

In this research, the critical social theory of Habermas $(1984,1987)$ is used as a classification scheme for analysing the alignment of communication and ICT applications in construction projects. Reasons for using Habermas' social action theory are the greater impact of his work on the information systems (IS) discipline than any other critical social theory school of thought (Ngwenyama and Lee, 1997), the existence of a theory about communication within his work (Ngwenyama and Lee, 1997), and the scope and depth of his treatment of social action (Hirschheim et al., 1996). Habermas (1984) describes four categories of social action: teleological action, normatively regulated action, dramaturgical action, and communicative action. Although each action type has a specific focus and orientation, together they represent different aspects of human behaviour in social settings (Ngwenyama and Lee, 1997). 
- Teleological action is defined as action undertaken by a single person who seeks to realise some goal. This type of action presupposes a relation between the actor and a world of existing states of affairs (objective world), either presently existing or producible through actions (Habermas, 1984). Teleological actions can be divided into instrumental actions and strategic actions.

- Instrumental action is directed towards achieving personal goals in a non-social way. An actor follows technical rules of action and tries to manipulate objects in ways that will serve his self-interest.

- In the concept of strategic action, an actor tries to achieve one's goals by influencing decisions of other actors. Each of the other actors "is oriented to his own success and behaves cooperatively only to the degree that this fits with his egocentric calculus of utility" (Habermas, 1984, p.88). When an actor tries to achieve his personal goals, he must cope with both cooperative and conflicting interests situations and find the best strategy to pursue his self-interest.

- Normatively regulated action is characterised as social action in which the primary intention of the parties involved is to fulfil reciprocal expectations by conforming their behaviour to shared norms and values. Social duties may then override the pursuit of personal goals. In this type of action, the actor can relate not only to an objective world (existence of states of affairs) but also to a social world ('existence' of norms). "A social world consists of a normative context that lays down which interactions belong to the totality of legitimate interpersonal relations" (Habermas 1984, p.88). When actors share such a context, they are referring to the same social world. This normative context exists as a categorically distinct world only when it is recognised as valid by actors; otherwise, this context simply becomes another feature of the objective world (White, 1988, p.37).

- Dramaturgical action relates to when social actors consider themselves as a visible audience of each other. "Here the focus is not on how an individual pursues a strategy or follows a set of normative expectations, but rather on how the performance of any action reveals something about the actor's subjectivity" (White, 1988, p.38). In this type of action, an actor behaves towards his own subjective world. Habermas (1984, p.91) defines this world "as the totality of subjective experiences to which the actor has, in relation to others, a privileged access". This subjective world is presented in a specific way to an audience of other actors.

- In the concept of communicative action, "actors seek to reach an understanding about the action situation and their plans of action in order to coordinate their actions by way of agreement" (Habermas, 1984, p.84). This requires "a cooperative process of interpretation aiming at situation definitions that are intersubjectively recognised" (Habermas, 1984, p.70). The context of the actor's pre-interpreted lifeworld plays an important role in reaching understanding. Out of this context, speakers and hearers "refer simultaneously to things in the objective, social, and subjective world in order to negotiate common definitions of situations" (Habermas, 1984, p.95).

When ICT was developed, designers built in certain interpretive schemes (rules reflecting knowledge of the work being automated), certain facilities (resources to accomplish that work), and certain norms (rules that define the organisationally sanctioned way of 
executing that work) (Orlikowski, 1992). Ngwenyama and Lyytinen (1997) use Habermas' typology for theorising about groupwork and groupware technologies. With this typology, Ngwenyama and Lyytinen (1997) critically analyse the implicit assumptions of groupwork embedded in groupware technologies, and their potential for supporting different social action types. In their framework, they distinguish instrumental action, strategic action, communicative action and discursive action. According to Lyytinen (1992), these four action types are prominent in information systems. Although Habermas does not distinguish discursive action, it could easily be added into his analysis (Lyytinen, 1992). Actors use discursive action when an agreement between a group of actors about a shared background can no longer be taken for granted (Hirschheim et al., 1996; Lyytinen, 1992; Ngwenyama and Lee, 1997; Ngwenyama and Lyytinen, 1997). Within this action type, actors try to discover or weight the arguments proposed for or against a message. Following Ngwenyama and Lyytinen (1997), the relation between four types of social action and the use of groupware are discussed next.

- Instrumental action. In groupwork, the instrumental manipulation of participants is pervasive in many group processes. Typical examples of instrumental action are document preparation and software design. The objects-of-work are often knowledge work such as reports, papers, plans, and engineering designs. Instrumental groupware supports the creation, manipulation and transformation of these objects-of-work.

- Strategic action. Strategic action is legitimate when it conforms to organisational norms, policies, authority structure, and the 'unwritten rules of the game'. Typical examples are negotiation and bargaining characterised by goal conflict, deception, unequal distribution of information and power. Although such processes are common in organisational life, there is not groupware available supporting on this type of groupwork.

- Communicative action. Successful communicative action depends on the actors' knowledge of language and the organisational context. By knowledge of language, Ngwenyama and Lyytinen (1997) mean competence in the usage of rules of syntax and semantic and universal rules of pragmatic behaviour. Communication groupware supports group interactions, so those group members understand each other. Computer mediated communication (CMC) groupware assumes communicative action as the focal point of groupware.

- Discursive action. Participants of discursive action draw upon a common medium of communication, protocols for interaction, and intuitive knowledge of the ground rules of discourse. Discursive groupware supports problem exploration and solving, argumentation and critical debate by systems such as meeting and decision support systems and issue based information systems.

\section{ICT applications in construction}

ICT was originally directed primarily at streamlining internal process. New ICT applications focus on the integration of different business processes. Many researchers have recently investigated inter-organisational use of ICT applications (e.g., Anumba and Ruikar, 2002; Deng et al., 2001; Thorpe and Mead, 2001; Weippert et al., 2002). 
These applications are based on the use of the internet and the World Wide Web (WWW). The World Wide Web enables users to share text, graphics, audio and video through 'pages' and 'hypertext' links (Tam, 1999). With the use of this ICT, it is possible to produce a seamless conduit of information flow between organisations in construction projects (Finch, 2000). Important trends within inter-organisational use of ICT are the support of project management and project collaboration (Anumba and Ruikar, 2002). Some advantages of these applications in construction projects are (Anumba and Ruikar, 2002, p.271):
“... easier management of construction projects, easier access to project information from anywhere at anytime, faster transaction time, better transparency in the exchange of project information, better collaboration between construction project partners, time savings for communication of project information, savings on project costs, and streamlined construction business processes."

Several researchers have investigated ICT applications based on the principles mentioned above:

- $\quad$ Tserng and Lin (2003) have developed an agent-based communication environment called Electronic Acquisition Model for Project Scheduling (e-AMPS). e-AMPS focuses on scheduling issues, one of the major management tasks involved in project control (Tserng and Lin, 2003, p.271). It offers a methodology for automating communication among participants (i.e., between contractor and sub-contractors) during the construction phase of multi-contract projects. These are projects that are composed of several independent sub-contracted sub-projects, some of which may be further divided into other sub-projects. In order to make appropriate decisions with regard to project control, participants need external real-time scheduling information (planning and progress). With the use of e-AMPS, the participants automatically acquire external scheduling information and provide other participants with this information. The sharing of scheduling information among participants is useful for predicting delays and taking any necessary precautions. This concept has been tested within a hypothetical project.

- Weippert et al. (2002) discuss an internet-based Construction Project Management (ICPM) central database system for the design, management, and construction of construction projects. This system is a web-based project management system. With the use of this system, project team members send, receive and manage correspondence, request for information, instructions, variations, drawings and the many other documents involved in the construction process. This system also provides a full document management system and bureau printing services online. This system has the potential for saving considerable time during various stages of a project by improving design and documentation quality, reducing re-entering of data, less corresponding of project documents, less checking, and less seeking of irrelevant details. Within the paper the final results, and recommendations of a case study have been presented. 
- Dawood et al. (2002) developed an information management system to improve coordination, distribution, storage and access of project information and data at the construction phase of the construction project. The system is based on evolving ICT facilities such as internet, World Wide Web (WWW), and database technology. The system is evaluated in a real-time project. Compared with a paper-based system, this system shows a saving of more than $90 \%$ in manhours, with estimated huge saving costs.

- $\quad$ Thorpe and Mead (2001) discuss the use of project-specific websites (PSWSs). These websites are electronic project-management systems that use the internet and a series of linked web pages to store and distribute project information. These websites have the potential to speed information transfer, reduce communication barriers, and improve teamwork. It creates a communication network that facilitates information pull, resulting in increased accessibility of information and eliminated gatekeeping, distortion, and overload. The use of project-specific websites is investigated in three case studies.

- Tam (1999) and Deng et al. (2001) discuss an internet-based project management system called Total Information Transfer System (TITS). This system comprises six major functions: data exchange, information exchange (e-mail), internet chat, live videocam, search engine, and auxiliary services. A part of the functions provided by TITS has been tested within a small residential project. This system has been used for facilitating communication between the main contractor's head office and site office. This showed that TITS can enhance information sharing between various parties in a construction project and offers several benefits (i.e., improved efficiency, better management and decision making, enhanced performance to construction firms and saving of money).

The characteristics of the ICT applications discussed above can be related to Habermas' action types. This confrontation shows which action types can be supported by the developed ICT in construction projects. The dominant action type is communicative action. With the use of ICT applications, actors try to reach an understanding about action situations and their plans of action in order to coordinate their actions. For example with the use of e-AMPS (Tserng and Lin, 2003), participants automatically communicate real-time scheduling information in order to make appropriate decisions with regard to project control. All other examples of ICT applications mentioned above share the same characteristics. They all try to improve coordination, distribution, storage and access of project information. Within all examples, communicative action is dominant.

Besides communicative action, however, it also seems that normatively regulated action can be supported by the developed ICT applications. When participants make arrangements about their communicative behaviour and the use of ICT, appropriate use of applications is the result of the conformation of behaviour to fulfil reciprocal expectations. These arrangements must be based on the coordination of actions. In that case, appropriate use of ICT applications is not the result of a behaviour based on cooperation, but a behaviour based on the fulfilment of reciprocal expectations.

So, action types that can be supported by developed ICT applications for construction projects are communicative action and normatively regulated action. 


\section{Communication in construction}

Earlier research showed that in construction projects, three important factors influencing the communication between participating organisations in construction projects are the contract, the interests of the people involved, and the language spoken by the people involved (Adriaanse et al., 2002):

- The roles and responsibilities of the people of different organisations involved form, the structure of construction process organisations. This structure formally determines which information is communicated with whom. The structure is consolidated in contracts. The contractual arrangements form the basis for what is communicated between the parties in a construction project. There is a great range of possible methods of organising the construction process each with its different contractual relationships (Hillebrandt, 1984). Two basic project structures are the traditional approach and the design and construct project.

- The interests of the people involved influence the way they communicate. In construction projects, intricately interdependent activities have to be carried out by distinct organisations with a diverse range of interests, which are often conflicting (Cheng et al., 2001; Loosemore, 1999; Kornelius and Wamelink, 1998). Conflicts of interests increase the importance of information as a source of power in negotiations and make people more secretive with it. Parties can manipulate information in their own favour (Loosemore, 1999; Pietroforte, 1997). The result can be a lack of open communication or sending unclear or uninformative messages.

- The language used by the people involved is influenced by their frames of reference. It is desirable that the language used in the communication process is similarly understood by the various participants (Bowen and Edwards, 1996). In construction projects, efficient communication is often made difficult by the different frames of reference of its participants (Pietroforte, 1997). The different frames of reference are the result of the different professional background of the parties involved (Cheng et al., 2001; Moore and Dainty, 2001). This can result in misunderstanding and misinterpretation.

These factors can be confronted with the social action types presented by Habermas $(1984,1987)$ (see Table 1). Using information as a source of power is a result of strategic action. This can result in sending unclear and uninformative messages and manipulating information flow to influence other actors to achieve one's goals. The tendency of actors to conform their behaviour to what is formulated in the contract (i.e. structure) has to do with normatively regulated action. Actors fulfil reciprocal expectations by conforming their behaviour to the contract. Communication between organisations is made difficult by differences in their frames of reference. Within both strategic action and normatively regulated action, misunderstanding and misinterpretation may occur because of these differences in frames of reference of different participants. 
Table 1 Action types and difficulties in communication in construction projects

\begin{tabular}{ll}
\hline Types of social action & \\
\hline Strategic action & Normatively regulated action \\
\hline Information as a source of power & Conformation behaviour to what is \\
Sending unclear and uninformative messages & $\begin{array}{l}\text { formulated in the contract } \\
\text { Misunderstanding and misinterpretation }\end{array}$ \\
\hline
\end{tabular}

So, action types that need to be supported by ICT applications are strategic action and normatively regulated action.

\section{Alignment between communication and ICT}

In order to enable effective and efficient communication between organisations in construction projects, ICT needs to be aligned with the actual communication processes. In former sections, the types of action that can be supported by ICT and those that need to be supported by ICT are discussed. From these discussions, it follows that communicative action and normatively regulated action can be enhanced by the present ICT applications and that strategic action and normatively regulated action need to be enhanced by ICT. Strategic use of available ICT applications may undermine the ICT designer's objectives resulting in limited and ineffective use of ICT. This problem is also recognised by several researchers mentioned in Section 3. Tserng and Lin (2003) mention the importance of unobstructed communication among all project participants, i.e. the complete sharing of scheduling information among project members. According to Weippert et al. (2002), ICT alone is not enough to guarantee improved quality and accuracy of project-related communication. They emphasise that (Weippert et al., 2002, p.114):

"All project participants and stakeholders need to be fully committed to using the new ICT tool or ICPM communication system, with 'buy in' and collaboration at the highest level within the participating companies, thereby reassuring and guaranteeing potential users of a 'corporate commitment'."

Tam (1999) mentions that the key to internet's success is the open and cooperative nature of its arrangements. Thorpe and Mead (2001) and Dawood et al. (2002) do not make any explicit comments according to the need of cooperation. Their selection criterion for case studies, however, shows that they attach importance to cooperative behaviour. One of their selection criteria is "the project has to use formal partnering or team-building arrangements" and "the project has to be procured through a form of partnering arrangement", respectively.

Thorpe and Mead (2001) mention that the use of project-specific websites (PSWSs) has the potential of eliminating gatekeeping (i.e., withholding information in order to gain competitive advantage). In that case, the use of PSWSs will reduce strategic action. We, however, do not agree with that. When, for example, a document is not stored directly, it will not be available for other participants. Gatekeeping (i.e., strategic action) is still a possibility. The success of the use of ICT is directly dependent on the users of this technology. Strategic action is a serious treat for the use of developed ICT applications for construction projects. 
If ICT is provided without people first fully embracing the concept, the overall process will fail to be effective (Hassan and McCaffer, 2002). ICT needs to be aligned with the communication processes in construction projects. This alignment needs attention because otherwise advances in ICT will not be utilised in construction in the future. In order to achieve a better alignment between communication and ICT applications in construction projects, two directions of change are possible.

The first option is that ICT is aligned to strategic action type. Communication in construction projects is determined by goal conflict, deception, unequal distribution of information, and power. It is for that reason there exists a need for designing ICT systems supporting strategic action. In that case, ICT is aligned to the existing behaviour. The second option is that communicative action becomes more prominent in construction. In that case, the ICT applications discussed in Section 3 (existing ICT) will be aligned with the behaviour of the parties involved.

In order to realise the alignment between ICT and communication, an improvement is required in the structural cooperation between ICT suppliers and user companies. Successful realisation of applications will generate follow-ups. When this alignment is realised, the opportunities provided by ICT will be extensively used in the construction industry.

\section{References}

Adriaanse, A.M., Voordijk, H. and De Haan, J. (2002) 'Preconditions of the use of ICT in construction projects', in Sadler, I., Power, D. and Dapiran, G.P. (Eds.): Integrating Supply Chains and Internal Operations Through eBusiness, Monash and Victoria Universities, pp.617-624.

Ahmad, U.A., Russel, J.S. and Abou-Zeid, A. (1995) 'Information technology (IT) and integration in the construction industry', Construction Management and Economics, Vol. 13, No. 2, pp.163-171.

Anumba, C.J. and Ruikar, K. (2002) 'Electronic commerce in construction - trends and prospects', Automation in Construction, Vol. 11, pp.265-275.

Baldwin, A.N., Austin, S.A., Hassan, T.M. and Thorpe A. (1999) 'Modelling information flow during the conceptual and schematic stages of building design', Construction Management and Economics, Vol. 17, No. 2, pp.155-167.

Bowen, P.A. and Edwards, P.J. (1996) 'Interpersonal communication in cost planning during the building design phase', Construction Management and Economics, Vol. 14, No. 5, pp.395-404.

Cheng, E.W.L., Li, H., Love, P.E.D. and Irani, Z. (2001) 'Network communication in the construction industry', Corporate Communications: An International Journal, Vol. 6, No. 2, pp.61-70.

Dawood, N., Akinsola, A. and Hobbs, B. (2002) 'Development of automated communication of systems for managing site information using internet technology', Automation in Construction, Vol. 11, pp.557-572.

Deng, Z.M., Li, H., Tam, C.M., Shen, Q.P. and Love, P.E.D. (2001) 'An application of the internet-based project management system', Automation in Construction, Vol. 10, pp.239-246.

DeSanctis, G. and Poole, M.S. (1994) 'Capturing the complexity in advanced technology use: adaptive structuration theory', Organization Science, Vol. 5, No. 2, pp.121-147. 
Egbu, C., Gaskell, C. and Howes, J. (2001) 'The role of organizational culture and motivation in the effective utilization of information technology for teamworking in construction', in Akintoye, A. (Ed.): 17th Annual ARCOM Conference, 5-7, September University of Salford, Association of Researchers in Construction Management, pp.91-100.

Finch, E. (2000) Net Gain in Construction: Using the Internet in the Construction Industry, Butterworth-Heinemann, Oxford.

Giddens, A. (1979) Central Problems in Social Theory: Action, Structure and Contradiction in Social Analysis, University of California Press, Berkeley, CA.

Giddens, A. (1984) The Constitution of Society: Outline of the Theory of Structure, University of California Press, Berkeley, CA.

Habermas, J. (1984) The Theory of Communication Action: Reason and Rationalization of Society (1), Beacon Press, Boston.

Habermas, J. (1987) The Theory of Communicative Action: Lifeworld and Social System (2), Beacon Press, Boston.

Hassan, T.M. and McCaffer, R. (2002) 'Vision of the large scale engineering construction industry in Europe', Automation in Construction, Vol. 11, pp.421-437.

Hillebrandt, P.M. (1984) Analysis of the British Construction Industry, MacMillan Publishers, London.

Hirschheim, R., Klein, H.K. and Lyytinen, K. (1996) 'Exploring the intellectual structure of information systems development: a social action theoretic analysis', Accounting, Management and Information Technologies, Vol. 6, Nos. 1-2, pp.1-64.

Kornelius, L. and Wamelink, J.W.F. (1998) 'The virtual corporation: learning from construction', Supply Chain Management, Vol. 3, No. 4, pp.193-202.

Loosemore, M. (1999) 'Responsibility, power and construction conflict', Construction Management Economics, Vol. 17, No. 6, pp.699-709.

Lyytinen, K. (1992) 'Information systems and critical theory', in Alvesson, M. and Willmott, H. (Eds.): Critical Management Studies, Sage Publications, London, pp.159-180.

Mohamed, S. and Stewart, R.A. (2003) 'An empirical investigation of users' perceptions of web-based communication on a construction project', Automation in Construction, Vol. 12, pp.43-53.

Moore, R.M. and Dainty, A.R.J. (2001) 'Intra-team boundaries as inhibitors of performance improvement in UK design and build projects: a call for change', Construction Management and Economics, Vol. 19, No. 6, pp.559-562.

Ngwenyama, O.K. and Lee, A.S. (1997) 'Communication richness in electronic mail: critical social theory and the contextuality of meaning', MIS Quarterly, Vol. 21, No. 2, pp.145-167.

Ngwenyama, O.K. and Lyytinen, K.J. (1997) 'Groupware environments as action constitutive resources: a social action framework for analyzing groupware technologies', Computer Supported Cooperative Work: The Journal of Collaborative Computing, Vol. 6, pp.71-93.

Orlikowski, W.J. (1992) 'The duality of technology: rethinking the concept of technology in organisations', Organization Science, Vol. 3, No. 3, pp.398-427.

Orlikowski, W.J. and Yates, J. (1994) 'Genre repertoire: the structuring of communicative practices in organizations', Administrative Science Quarterly, Vol. 39, pp.541-574.

Pietroforte, R. (1997) 'Communication and governance in the building process', Construction Management and Economics, Vol. 15, No. 1, pp.71-82.

Tserng, H.P. and Lin, W.Y. (2003) 'Developing an electronic acquisition model for project scheduling using XML-based information standard', Automation in Construction, Vol. 12, pp.67-95.

Tam, C.M. (1999) 'Use of the internet to enhance construction communication: total information transfer system', International Journal of Project Management, Vol. 17, No. 2, pp.107-111.

Thorpe, A. and Mead, S.P. (2001) 'Project-specific websites: friend or foe?', Journal of Construction Engineering and Management, Vol. 127, No. 5, pp.406-413. 
Wamelink, J.W.F. and Wortmann, J.C. (1996) 'A control-oriented approach to management information systems in construction', The International Journal of Construction Information Technology, Vol. 4, No. 2, pp.29-44.

Weippert, A, Kajewski, S.L. and Tilley, P.A. (2002) 'Internet-based information and communication systems on remote construction projects: a case study analysis', Construction Innovation, Vol. 2, pp.103-116.

White, S.K. (1988) The Recent Work of Jürgen Habermas: Reason, Justice and Modernity, Cambridge University Press, Cambridge. 